\title{
The revised aeromagnetic anomaly map of Italy
}

\author{
Fabio Caratori Tontini $\left({ }^{1}\right)\left({ }^{2}\right)$, Paolo Stefanelli $\left({ }^{1}\right)\left({ }^{2}\right)$, Italiano Giori $\left(^{3}\right)$, \\ Osvaldo Faggioni $\left({ }^{1}\right)\left({ }^{2}\right)$ and Cosmo Carmisciano $\left({ }^{1}\right)\left({ }^{2}\right)$ \\ $\left.{ }^{(}{ }^{1}\right)$ Istituto Nazionale di Geofisica e Vulcanologia, Sede di Portovenere, Fezzano (SP), Italy \\ ${ }^{(2)}$ Consorzio Universitario della Spezia (Cunispe), Istituto di Geofisica Marina, La Spezia, Italy \\ (3) Eni Spa-Exploration \& Production Division, S. Donato Milanese (MI), Italy
}

\begin{abstract}
This paper presents the revised aeromagnetic anomaly map of Italy and its surrounding seas, projected at reference altitude of $2500 \mathrm{~m}$ and geomagnetic epoch 1979.0. The magnetic data set used for the map compilation is composed of the total intensity field data acquired partly during the aeromagnetic surveys performed by the Italian National Oil Company (Agip - Direzione Esplorazione Idrocarburi) between 1971 and 1980, and during the new surveys committed by the Geophysical Corporate Services of Eni Spa - Exploration \& Production Division in the years 2001-2002. In both campaigns the recorded data were very dense and uniformly distributed over the examined area. A detailed re-processing of this data set and a re-organization into a new digital database were carried out. The re-processing was done using modern adequate techniques, obtaining a remarkable exploitation of the data information content. The result is a colour shaded relief map that shows on a large scale many of the structural lineaments of the Italian area. The inclusion of a larger number of data and the subtraction of an appropriate magnetic reference field are the main reasons of an enhancement in the anomaly definition. This new map replaces the previous Agip version, and aims to become the reference aeromagnetic cartography of the Italian area. We think this work will be useful both for researchers interested in large scale tectonic studies, and for anyone interested in the investigation of smaller scale structures, such as volcanic complexes or infra-sedimentary magnetic bodies, as well as for mining research.
\end{abstract}

Key words geomagnetism - aeromagnetic anomaly magnetic methods - aeromagnetic cartography

\section{Introduction}

Potential field imaging has a great importance in mapping geologic structures. At a reasonable cost it is possible to cover large areas in a short time, and being not invasive, this technique does not alter the equilibrium of the investigated area. Magnetic field data obviously are particularly ef-

Mailing address: Dr. Fabio Caratori Tontini, Istituto Nazionale di Geofisica e Vulcanologia, Sede di Portovenere, Villa Pezzino, Via Pezzino Basso 2, 19020 Fezzano (SP), Italy; e-mail: caratori@ingv.it fective in mapping structures characterized by major magnetic susceptibilities, such as magmatic or infra-sedimentary ophiolitic bodies.

Moreover large scale maps are particularly effective when applied to the study of the tectonic setting because they permit extraction of information about the main lineaments and structural trends. On the contrary, if the database is characterized by an intensive sampling, it is possible to map smaller areas with dense data to extract information about high frequency components of the field connected with shallower sources, such as volcanic complexes or outcropping susceptive lithologies. The data that compose the new aeromagnetic anomaly map have been assembled into a digital database in such a way as to permit differentiated analyses finalized to compile different scale maps, according to user needs. 
The present magnetic cartography on the Italian area is based on two main works: the aeromagnetic anomaly map of Italy (Agip and SGN, 1994) compiled by Agip, whose data have been partly used in this work, and the shaded relief magnetic anomaly map at sea level, by Chiappini et al. (2000), compiled with the off-shore data obtained by the Osservatorio Geofisico Sperimentale (OGS) of Trieste and the ground data from the repeat station network and 2nd order station network by the Istituto Nazionale di Geofisica e Vulcanologia (INGV). The latter map shows a significant result obtained merging ship-borne and ground data sets acquired with different methodologies, instrumentations and date of surveys.

The previous Agip map realized for specific mining targets shows some peculiarities in the data processing. These characteristics are partly due to old techniques used at that time, but mostly depend on the selection of a specific geomagnetic reference model especially devoted to the study of mining problems. Infact, the main field was subtracted using an interpolating surface composed of the envelope of local planes, obtained from horizontal gradient studies (Cassano, 1984). The residual map, obtained after this procedure, shows the phenomenon of a linear trend aligned NNW-SSE, with an average slope of $0.5 \mathrm{nT} / \mathrm{km}$. This map was thus appropriate for industrial applications, showing some problems when used for structural studies, where the trend effects can mask or even deteriorate the large wavelength anomalies. However the aeromagnetic data, that are acquired at a determined height over the topographic surface, naturally filter out geologic noise coming from small shallow magnetic bodies and for this reason they are very useful in the analysis of deep large scale structures.

The Consorzio Universitario della Spezia (Cunispe), whose researchers are currently in the Istituto Nazionale di Geofisica e Vulcanologia, in cooperation with Eni Spa - Exploration \& Production Division, has updated the old aeromagnetic anomaly map by re-processing the original data set. These data in fact show a very high potentiality, because of the care ap- plied during their acquisition, their remarkable density and the homogeneous and uniform distribution over the covered areas. The occasion for this global revision, also derived from the possibility to insert in the map some «patch» areas surveyed by Eni in 2001-2002 to fill some gaps in the previous coverage.

The integration was done through the application of procedures able to make all available measurements comparable. The different survey epochs and the different flight altitudes of each of the separate micro-surveys were integrated to converge into a systematic national coverage. The final map, where the old fictitious trend is now removed, shows remarkable progress with respect to the original aeromagnetic Agip map, also for a better localization and definition of the magnetic anomalies generated by the shallower sources.

In the following sections we will describe the data organization and the processing methodology in detail. Particular attention will be taken to explain the integration procedure that has a capital importance in merging the single micro-surveys, separate in space and time, that compose the global map.

\section{Data characteristics and organization}

The data that have been processed to compile the new aeromagnetic anomaly map come mainly from 36 original micro-surveys executed by Agip (Direzione Esplorazione Idrocarburi) from 1971 to 1980 over the entire national territory and the nearby seas. These data have been integrated with 5 recently surveyed areas acquired in 2001-2002 in the context of a joint project between Eni and Cunispe (Eni Spa - Exploration \& Production Division Project 4700000254/MR1). The geographical localization of these more recently studied areas is Ancona off-shore, Molise on/off-shore, North-East Calabria on/off-shore, Sicily onshore and Southern Sicily off-shore. Figure 1 shows the total line-path of the global survey. The flight lines, mainly oriented in SW-NE direction, are intersected by orthogonal control tie lines. The total length of the surveyed profiles amount to $326823 \mathrm{~km}$, and the surface 
Table I. Survey codes for the magnetic provinces and associated statistics. Recently areas surveyed by Eni are labelled by the codes $1-5$.

\begin{tabular}{|c|c|c|c|c|c|c|}
\hline \multirow{2}{*}{ Province } & \multirow[t]{2}{*}{ Survey code } & \multirow[t]{2}{*}{ Records } & \multicolumn{2}{|c|}{ Latitude } & \multicolumn{2}{|c|}{ Longitude } \\
\hline & & & $\min$ & $\max$ & $\min$ & $\max$ \\
\hline Alps-Po Valley & $\begin{array}{c}58-59-60-67- \\
70-87-171\end{array}$ & 512622 & $43^{\circ} 46^{\prime} 58^{\prime \prime}$ & $47^{\circ} 03^{\prime} 07^{\prime \prime}$ & $06^{\circ} 36^{\prime} 07^{\prime \prime}$ & $13^{\circ} 53^{\prime} 27^{\prime \prime}$ \\
\hline $\begin{array}{l}\text { Apennine- } \\
\text { Adriatic }\end{array}$ & $\begin{array}{c}1-5-69-71-75- \\
79-86-63.1-63.2\end{array}$ & 300901 & $41^{\circ} 09^{\prime} 52^{\prime \prime}$ & $45^{\circ} 01^{\prime} 23^{\prime \prime}$ & $11^{\circ} 07^{\prime} 31^{\prime \prime}$ & $17^{\circ} 14^{\prime} 41^{\prime \prime}$ \\
\hline Tyrrhenian & $\begin{array}{c}56-57-66-68-72- \\
74-80-81-83-85\end{array}$ & 678863 & $37^{\circ} 26^{\prime} 21^{\prime \prime}$ & $45^{\circ} 14^{\prime} 49^{\prime \prime}$ & $07^{\circ} 57^{\prime} 53^{\prime \prime}$ & $16^{\circ} 01^{\prime} 48^{\prime \prime}$ \\
\hline $\begin{array}{l}\text { Siculan- } \\
\text { Calabrian- } \\
\text { Ionian }\end{array}$ & $\begin{array}{c}2-3-4-13-61-62- \\
64-65-73-76-77- \\
78-82-84-121\end{array}$ & 1339449 & $35^{\circ} 13^{\prime} 55^{\prime \prime}$ & $42^{\circ} 33^{\prime} 49^{\prime \prime}$ & $11^{\circ} 30^{\prime} 03^{\prime \prime}$ & $19^{\circ} 59^{\prime} 51^{\prime \prime}$ \\
\hline
\end{tabular}

covered by the global survey measures approximately $783576 \mathrm{~km}^{2}$.

The 36 micro-surveys executed by Agip are characterized by an average line spacing of 5$10 \mathrm{~km}$ and an average tie line spacing of $10-15$ $\mathrm{km}$. The sampling step ranges from 0.05 to $0.25 \mathrm{~km}$. There is an exception that is represented by a small area located between Crotone latitude and the Messina Straits, where the data furnished by Agip were organized into a $2 \mathrm{~km}$ cell grid. The typical wavelength of the magnetic field in this zone is significantly greater than $4 \mathrm{~km}$ so that this difference in the data distribution does not affect the global product. The new micro-surveys performed by Eni are more accurate because the average spacing between the lines is $2-5 \mathrm{~km}$ and 5-10 $\mathrm{km}$ for the tie lines, with an average sampling step of $0.05 \mathrm{~km}$.

The total intensity magnetic field in both the campaigns was measured by means of an optically pumped caesium magnetometer with high resolution $(0.01 \mathrm{nT})$. At the center of each continental micro-survey, or in the nearby coast in marine acquisitions, a base station was installed to record the geomagnetic variation during the aeromagnetic flights (Parkinson and Jones, 1979). The geographical localization was evaluated using Loran $\mathrm{C}$ receivers and photographic cameras for the profiles location. In the case of the recent micro-surveys by Eni the position was directly acquired by the GPS system. The flight altitudes were at different levels in the range from 4800 feet over the marine areas, to 13000 feet in the Alpine region, depending on the topographic pattern of the surveyed area.

Data from each single micro-survey were labelled using a numerical code that permits their identification, according to the original denomination of the ASCII file containing the data. This data organization, that was also implemented in the digital integrated database, has the great advantage of making consultation easy and efficient also for a detailed analysis focused on a particular area. The user, either for structural studies or mining/petroleum research, can then select only those surveys effectively belonging to the examined area, with a consequent faster execution time and with the possibility to extract grids with small edge cells and to print very detailed maps of the selected areas. Depending on specific geomagnetic styles, in addition to different geographical and geological characteristics, the surveys are grouped in four main magnetic provinces as shown in table I, where some information is also presented. Figure 2 shows the position and the geometry of the polygons enclosing each of the 41 areas defined by any separate micro-survey. The joint comparison between fig. 1 and fig. 2 reveals the great accuracy in the coverage of the entire Italian territory. 


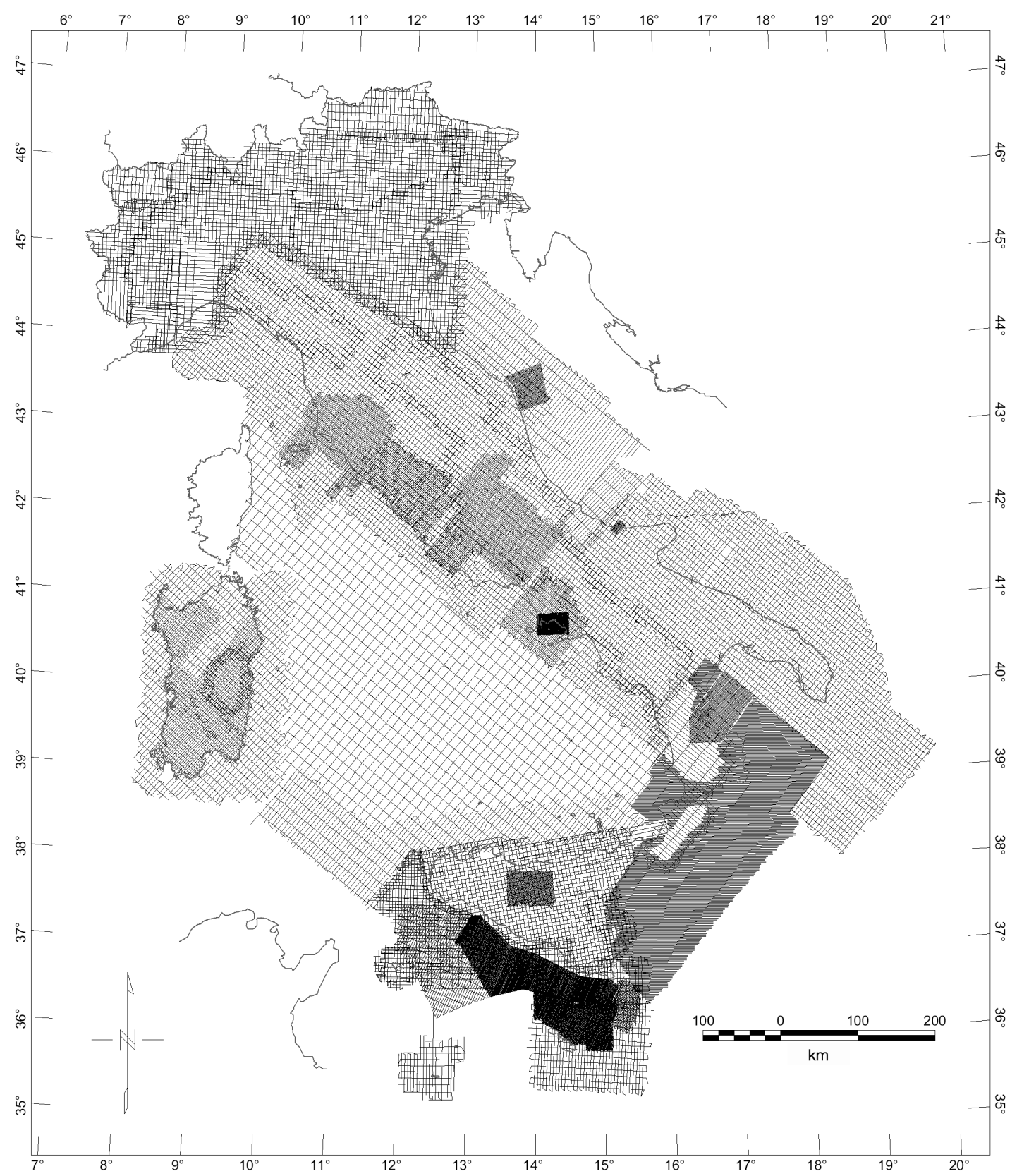

Fig. 1. Line path orientation and density of the aeromagnetic compilation. 


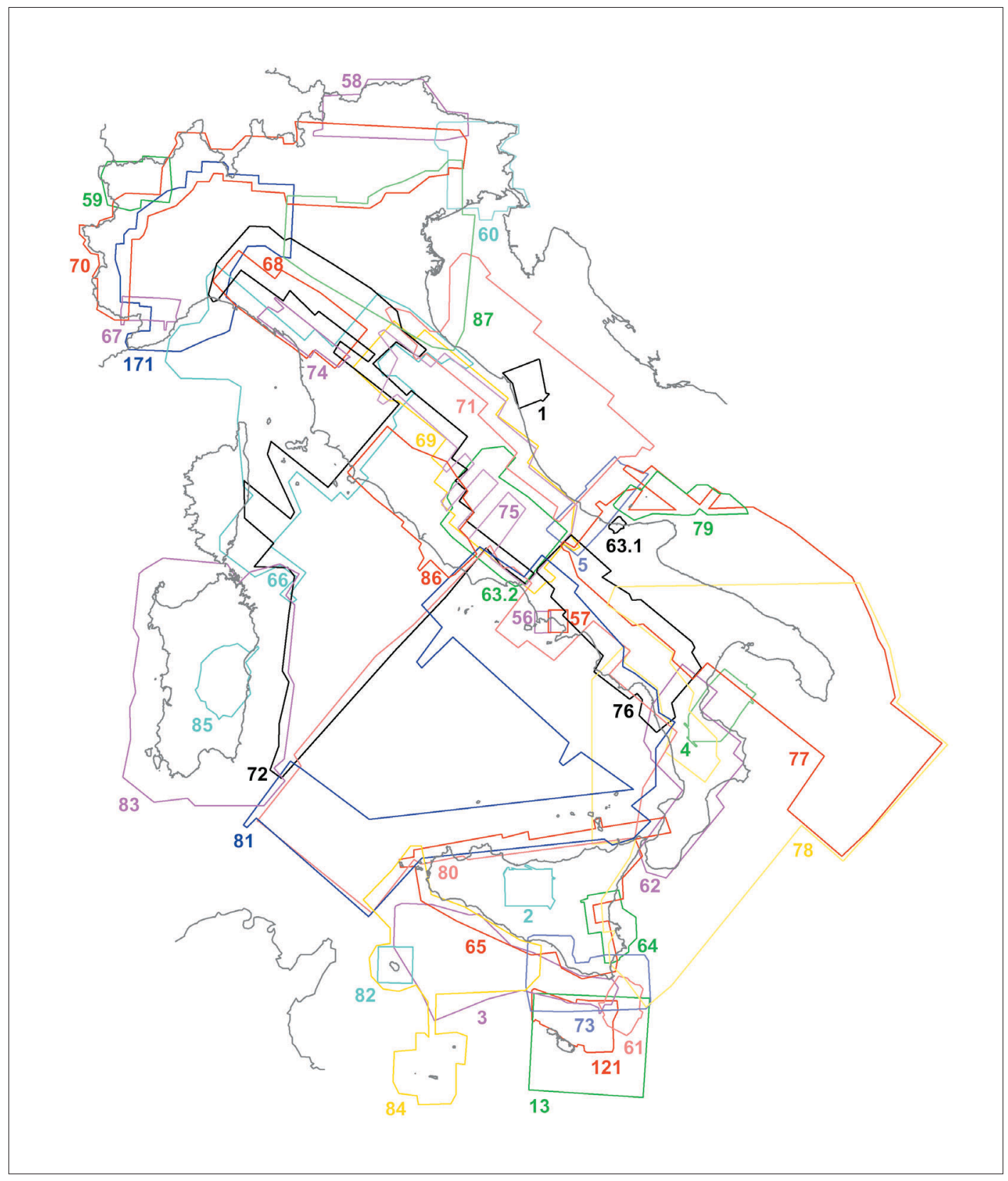

Fig. 2. Micro-surveys geometry and distribution of the aeromagnetic acquisition. 


\section{Data processing and integration methodology}

First of all, we performed a careful standard quality control of the database. Each single line was analysed to avoid residual spikes or double records, so that the entries of the database were fully employable. Data processing was then performed in different ways, depending on the level of rawness of the data acquired by Eni with respect to the original data partially processed by Agip. The recent micro-surveys in fact, were organized into an ASCII file divided into different channels. Moreover the coordinates channels, the total intensity magnetic field, and the associated magnetograms from a coherent base station were available to perform the time variation subtraction (Faggioni and Caratori Tontini, 2002). The application of the statistical leveling to avoid intersection errors between the lines and the tielines, and the micro-leveling (Minty, 1991; Ferraccioli et al., 1998) to reduce the effects of linepath stretching led to a correct observed field where the time variation is filtered.

The Agip data format instead posed some problems for the organization of the working procedure. The original channels were not always available. The only channel common to each of the 36 micro-surveys was the residual field, i.e. the magnetic field obtained after subtraction of the time variation, and after the residuation of the reference field. This channel was used as the starting point for the integration procedure. The data were assumed to be effectively time reduced by Agip, but they were affected by the subtraction of that particular reference field, composed of simple bi-dimensional interpolating surfaces (planes) with characteristics typical of each single micro-survey, with a loss of generality. The subsequent step to converge towards unification was the removal of the effects of the reference field surface built with the local horizontal gradients found in Cassano (1984). The planes relevant to each micro-survey were added to the anomaly field to obtain the assumed correct observed field. In some cases the statistical leveling and microleveling was performed to produce a data channel without fictitious anomalies at the crossing points or elongated anomalies aligned as the line-paths. Each of the 41 micro-surveys had a particular coordinate system. To achieve an efficient merging we projected every data set into a common cartographic system: Transverse Mercator Projection with Latitude $0^{\circ}$, Longitude $14^{\circ}$, False East 1500000 $\mathrm{m}$ and False North $0 \mathrm{~m}$, using the WGS84 Datum. The subtraction of the reference field IGRF79 led to a correct global anomaly field.

All data were projected to the common altitude of $2500 \mathrm{~m}$. This altitude represents an average value between the various original altitudes, typical of each micro-survey, that is a good balance between the high frequency noise filtering and the signal power natural suppression. The procedure was achieved through the Bottom Reduction Method (BTM) procedure developed by Cunispe (Faggioni et al., 2001), permitting the comparison among various micro-surveys and avoiding the generation of high frequency spurious signals when the data are downward continued. The data are projected over the topographic surface according to the following formula:

$$
\begin{aligned}
& \Delta F_{c}^{L, H}(\varphi, \lambda) \equiv \Delta F^{L, H}(\varphi, \lambda)+\frac{1}{2} \cdot d(\varphi, \lambda) . \\
& \cdot K^{L, H} \cdot \frac{\Delta F^{L, H}(\varphi, \lambda)}{\left|\Delta F_{\max }^{L, H}\right|}
\end{aligned}
$$

where $\varphi$ and $\lambda$ are the geographical coordinates; $\Delta F_{c}^{L, H}(\varphi, \lambda)$ is the low (high) frequency BTM projected intensity of the geomagnetic anomaly field; $\Delta F^{L, H}(\varphi, \lambda)$ is the low (high) frequency intensity of the geomagnetic anomaly; $d(\varphi, \lambda)$ is the depth of the topographic surface; $K^{L, H}$ is the low (high) frequency vertical gradient; $\Delta F_{\max }^{L, H}$ is the low (high) frequency maximum intensity of the anomaly field.

The operator of eq. (3.1) spreads the magnetic data values measured at a certain altitude over a reference topographic surface (in this case a plane surface at $2500 \mathrm{~m}$ ), according to different vertical gradients defined by the $K$ parameter. The convolution of the high and low frequency projected field gives the BTM corrected anomaly field.

The last integration was done reducing the noise in the bordering areas, statistically levelling lines coming from a region over the lines of the bordering region and vice versa (Minty et al., 


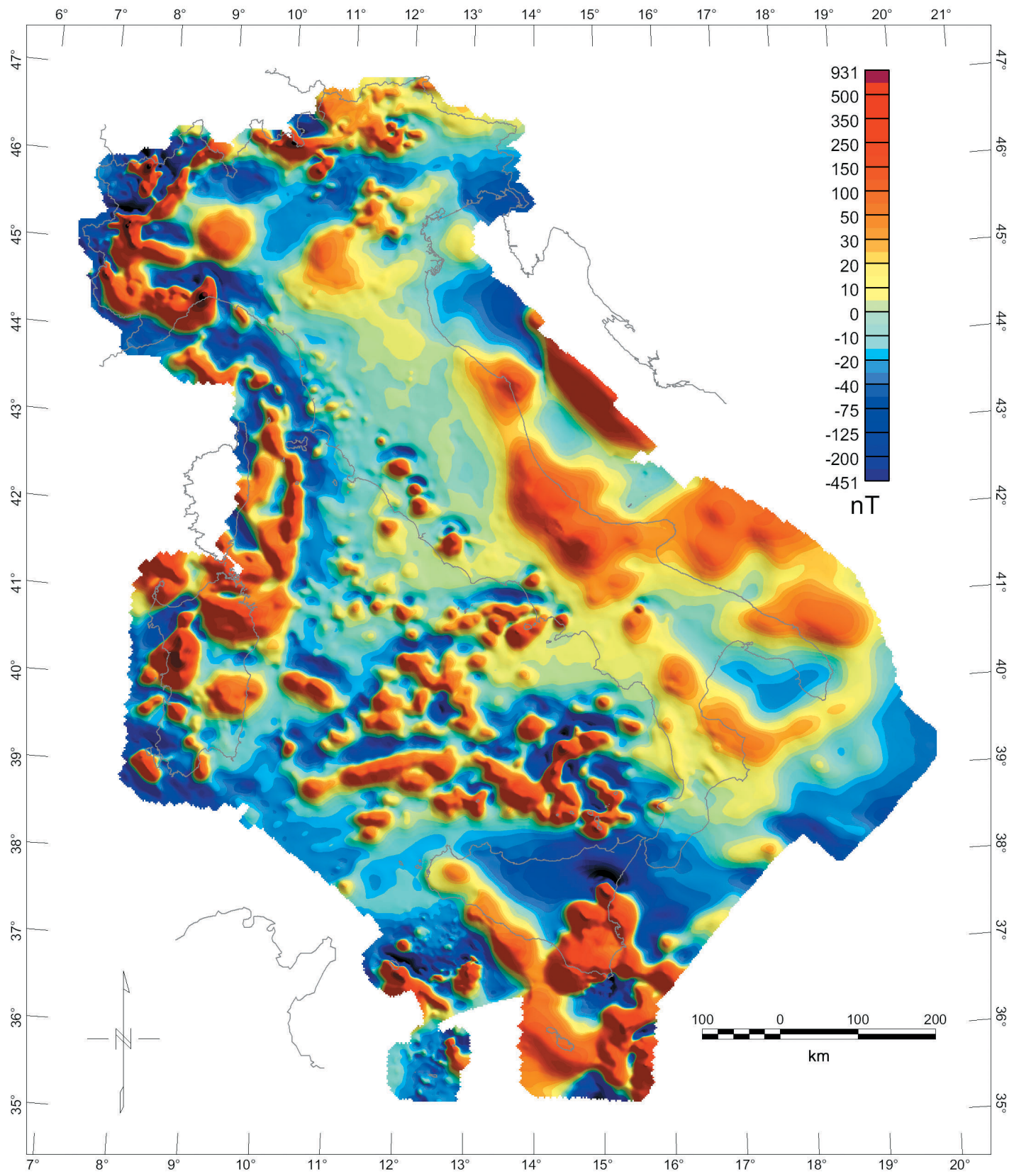

Fig. 3. Colour shaded relief map of the aeromagnetic anomaly field. 
2003). This step was particularly time-consuming because the number of overlapping areas is considerable. When present, residual trends were suppressed by polynomial subtraction in a least squares sense (Bullard, 1967). The final product is an A0 colour shaded relief map with scale 1:1500000, contour interval $10 \mathrm{nT}$, and illumination with inclination $45^{\circ}$ and declination $45^{\circ}$, with a grid cell size of $2 \mathrm{~km}$. This map is also reported in this paper as fig. 3, where only the colour shaded relief map is drawn with no contour lines. The data range measures $1500 \mathrm{nT}$, and the palette was chosen to satisfy graphic requirements that give both a global vision of the anomalies pattern according to their various typical wavelengths, and to show their main geologicstructural trend signatures.

It is quite difficult to assess a statistical error estimate for each single datum. The cross-over error analysis would permit this quantification in principle at least in the subset of the crossing points, that are approximately 30000 . A graphic representation of this error distribution is problematic, however a detailed statistical analysis has demonstrated that it is almost uniformly distributed over the whole data range. The absolute error is generated mostly by the measurement procedure (height and lag error, magnetic measurement statistic fluctuation, positioning, ...) and by residual time variation effects, but scarcely ever exceeding $5 \mathrm{nT}$. The gridding procedure obviously introduces further approximations caused by the interpolation (minimum curvature method), depending on its typical parameters (interpolation radius, grid cell size, low-pass desampling factor, ...). The final associated error is thus subjective and difficult to evaluate, but it belongs to the graphic production stage and it does not corrupt the digital database itself.

\section{Conclusions}

The updated aeromagnetic anomaly map is proposed as a new starting point for structural regional studies, for an enhanced consistency of the magnetic data with respect to the previous version, due to the application of more appropriate and modern processing techniques. The associated database has been structured to help the user in the choice of the minimum amount of data needed to perform the analysis, with a consequent reduction of the time execution and the machine computation, and can be upgraded without difficulty incorporating newly surveyed data. The map, born to be used by Eni Spa - Exploration and Production Division for petroleum and mineral exploration, reflects the actual Italian tectonic setting, stressing its main lineaments. We emphasize the usefulness of this tool also for anyone who is interested in studying the evolution of this area to develop new interpretations. The masking effects of the geomagnetic linear trend that was evident in the previous version has been removed with a consequent increase in the anomaly definition minimizing previous existing long wavelength errors. The aeromagnetic map, if compared to the map at sea level of Chiappini et al. (2000), obviously shows a lower signal power because of the greater altitude, that however is balanced by the very dense number of records $\left(>2.8 \times 10^{7}\right)$. Joining together the information coming from the two maps, we expect that it will be possible to have a very powerful tool for interpreting structural setting of the Italian region.

\section{Acknowledgements}

The authors are grateful to Eni Spa - Exploration \& Production Division for granting permission to publish the data. Ivo Loretti of Eni Spa Exploration \& Production Division is appreciated for his valuable contribution during the acquisition of the new micro-surveys. Dr. Antonio Meloni and Dr. Massimo Chiappini of Istituto Nazionale di Geofisica e Vulcanologia are particularly appreciated for their encouragement about publishing this work and for their helpful revision. We thank also Dr. Angelo De Santis of Istituto Nazionale di Geofisica e Vulcanologia for his useful criticism essential to improve this work.

Note: copies of the A0 aeromagnetic anomaly map can be obtained free of charge, after Eni Spa - Exploration \& Production Division Management approval, sending a request to Eni reference author at the following address: Dr. Italiano Giori, Via Emilia 1, 20097 San Donato Milanese (MI), Italy; e-mail: italiano.giori@agip.it 


\section{REFERENCES}

AGIP Spa and SGN (Servizio Geologico Nazionale) (1994): Carta Aeromagnetica d'Italia, Scala 1:1000000 (Istituto Poligrafico Zecca dello Stato).

BullarD, E.C. (1967): Removal of trend from magnetic surveys, Earth. Planet. Sci. Lett., 2, 293-300.

Cassano, E. (1984): Rilievi magnetici per la ricerca mineraria, in Atti del Primo Convegno di Geomagnetismo, Pubblicazioni dell'Istituto Nazionale di Geofisica, 117-163.

Chiappini, M., A. Meloni, E. Boschi, O. Faggioni, N. BeVERINI, C. CARMISCIANO and I. MARSON (2000): Shaded relief magnetic anomaly map of Italy and surrounding marine areas, Ann. Geofis., 43 (5), 983-989.

FAGGioni, O. and F. CARATORI TONTINI (2002): Quantitative evaluation of the time-line reduction performance in high definition marine magnetic surveys, Mar. Geophys. Res., 23 (4), 353-365.

FagGioni, O., N. Beverini, C. Carmisciano and I. Gior
(2001): A metrologic method of anomaly field amplitude bottom reduction in undersampled geomagnetic marine surveys, Mar. Geophys. Res., 22, 63-79.

Ferraccioli, F., M. Gambetta and E. Bozzo (1998): Microlevelling procedures applied to regional aeromagnetic data: an example from the Transantartic Mountains (Antartica), Geophys. Prospect., 46, 177-196.

MinTY, B.R.S. (1991): Simple micro-levelling for aeromagnetic data, Explor. Geophys., 22, 591-592

Minty, B.R.S., P.R. Milligan, A.P.J. LuYendyk and T. MACKEY (2003): Merging airborne magnetic surveys into continental-scale compilations, Geophysics, 68, 988-995.

PARKINSON, W.D. and F.W. JonES (1979): The geomagnetic coast effect, Rev. Geoph. Sp. Phys., 17, 1999-2015.

(received August 22, 2003

accepted August 26, 2004) 